\title{
EDITORIAL
}

\section{Introduction: Some Thoughts on Research Programs in Architecture}

\author{
Wes Aelbrecht*
}

Each year, the Bartlett School of Architecture doctoral program stages an annual conference to showcase the best research done by doctoral students from its Architectural Design and its Architectural History and Theory programs. Students either deliver a lecture or exhibit a visual work in the lobby spaces of the Bartlett School. While each year the conference is an enormous success, few traces remain of these 'works in progress.' Occasionally, a few small publications circulate with some highlights of the day, but it is fair to say that the impact remains modest. At Opticon1826, UCL's open access, peerreviewed journal, we therefore collected a selection of the 2013 PhD Research Projects conference papers in a special issue dedicated to research on the built environment. Opticon1826 is a platform where the conference presenters extend their experience by translating their work from a conference script into a peer-reviewed journal article.

What made the 2013 conference groundbreaking was that presentations came not only from the doctoral researchers in Architectural Design and Architectural History and Theory at the Bartlett, but also from researchers in Anthropology at UCL, and from researchers at the Royal Academy of Music. Combining architectural designs with the history and theory of architecture remains innovative and challenging. Where

\footnotetext{
* Guest Editor, Opticon1826,

UCL, United Kingdom

w.aelbrecht@ucl.ac.uk
}

else within the borders of UCL can one explore in depth a theoretical or practical question about space through an artistic practice? Instead of a text-based thesis, doctoral candidates from Architectural Design submitted a text-based investigation alongside an artistic intervention, developed in dialogue with Theory and History. By bringing together different disciplines from within UCL, both the conference and this special issue offer a reflection on the interrelation between the theory and history of architecture and architectural practice, and, furthermore, demonstrate the openness of the architectural discipline through the acceptance of various forms and subjects of research. Indeed, the days that architectural history dealt solely with the history of styles or with the architect as the sole author of a building are gone, a point well demonstrated at the conference. Instead of defining a style or celebrating the architect as the genius builder, the work collected in this special issue deals instead with processes of architecture before, during, and after construction. Some authors in this volume created decay (Sotomayor 2014), others performed Antarctica's archive (Gould 2014) buried social housing estates (Roberts 2014), complicated nation-state narratives (Amygdalou 2014), drew landscape-as-sound (Buck 2014), staged an ants dance (Palmer 2014), exposed the irony in the meaning of home in the gypsy legislation (Hoare 2014), unearthed the relation between the streets of London and financial transactions (Thomas 2014), or 
mapped the physicality of instrumental performances (Masing 2014).

In their introductory statement in the conference booklet, conference co-ordinators Amy Thomas and David Roberts identified the three underlying themes of the conference: system of control, decline and rebirth, and materiality versus immateriality:

One dominant discussion permeating many papers is the role of architecture in producing, or being produced by, systems of control. Such conversations range from the societal level, examining violent architectural interventions by the state to microscopic manipulations of entomological behaviour and to seemingly abstract systems in financial and industrial sectors in which regulated processes become a kind of dynamic architecture. The ethics and aesthetics of these discussions are probed by a variety of methodological approaches, from archival research into architectural plans to scientific experimentation with animals.

In a similarway, the theme of perceived decline and renewal is expressed in multiple mutations ranging from the political to the parasitical: magnified investigations of biological decay and documentary evidence of geological erosion become inadvertent yet poignant metaphors for broader discussion of cyclical deterioration and 'regeneration' of social housing. The practices of drawing, filming, painting, performing and writing act as conceptual, collaborative and reflective tools to cast new light on these shared considerations.

This permutation from matter to metaphor is reflective of a broader antipathy to binary classification weaving throughout the research in relation to the question: what is architecture?
In particular, the dichotomy of materiality and immateriality. (Roberts and Thomas 2013: 7)

To many insiders, and most outsiders, the architectural practice and the history and theory of architecture are two separate and distinct entities. In architectural practice, it is assumed that students and practitioners deal with the design of buildings for the present condition or for some utopian future, while in architectural history and theory, students, critics, and historians deal only with the past. Considering that, on the one hand, history asks questions framed most often through present events, and loaded with concern for the future, while on the other hand architectural designs do not suddenly spring out of the heads of the architect, but rather slowly develop from generation to generation, we have to see the practice and the history and theory of architecture as two entities of architecture that share similar concerns and ask similar questions.

It is no surprise, then, that as Roberts and Thomas identified, interdisciplinarity was one of the aims of the conference, referring thereby to the work of the philosopher Julia Kristeva and the architectural historian Jane Rendell. Roberts and Thomas stated that their hope was that the conference would open up '...processes and relationships of doctoral research to critical and creative evaluation, inspiring interdisciplinary exchange and arousing a curiosity in the reader to engage in the dialogue, asking questions of each other and of themselves' (Roberts and Thomas 2013: 7). Collected for the first time in this issue, we can finally reflect on the question: what can the fields of architectural designs and architectural history and theory learn from one another? I would like to suggest that the answer can be found in the idea of translation and narration in fieldwork, research methods, and presentations and disseminations of research.

Of particular interest are the strategies of presentation and representation of the architectural designers' subject matters, 
research methods, and findings. All too often in academia we measure research findings in terms of impact and applicability in the field. We also tend to think of research questions, methods, and findings presented in the conventional format, such as the essay. Some contributors challenged this way of thinking by designing visual storyboards based on films, as seen through Palmer's stark images (Palmer 2014) in the staging of ants in a dance, an aesthetic presentation inspired by Comic Noir layouts. David Buck also challenged traditional forms of presentation with his notations of sound in the landscape (Buck 2014). Polly Gould created a script (Gould 2014) to narrate us through a slide program in the search for the conditions that created and re-created Antarctica. Others, like Roberts, performed and celebrated the loss of one of London's many social housing projects (Roberts 2014), or, in Camila Sotomayor's piece, designed visual statements about the intertwining and cyclical relation that exists between decay and rebirth (Sotomayor 2014).

In all of these works, the idea of translation is key, by which I mean translating findings from theoretical questions and fieldwork to an art practice (i.e. music, drawing, painting, photography, film), and then finally to a larger audience, the reader, listener, or viewer. The dialogue between audience and theory is also an integral part of most practices. This triangulation between the author's research, the artwork, and us is crucial and is one of the strong points in the creative works presented in this volume. Indeed, the different ways in which all of these authors narrate us through their experience sets up a relation with others. Roberts placed us in front of the current inhabitants of social housing projects and the immoral representation of social housing schemes. Roberts' work (Roberts 2014) introduces new ways to bring research back in to the field, from where it came in the first place, by reinventing the classic architectural tour and making it more participative and reflective. Gould's script (Gould 2014) asked us to question the archive and allowed us to construct our own, whereas Palmer's work (Palmer 2014) asked us to question the absurdity of technology that controls our lives instead of simplifying it. Masing asked us to take into account the overlooked element in music: the experience of the physicality of musical instruments in space (Masing 2014). Buck's research asked us to rethink representation of landscape by including sound in the drawing of landscapes (Sotomayor 2014). Sotomayor's work presented here is part of an Institute of Decay (Sotomayor 2014), which she founded in 2013, that aims to bring together various thinkers and practitioners working on cycles of decay and rebirth, and thus enables her to create a large distribution center to tackle the strong focus on 'ruin porn' in recent years.

Opening up the discourse of architectural history and theory by welcoming art practices into its domains demonstrates that leaving the conventional methods and narrative structures sheds new light on previously unquestioned topics. It also emphasizes the constructed nature and subjectivity involved in doing research, an issue that has always been important at the Bartlett, a school that functions as an epicenter of feminist theory in architecture, headed by figures such as Jane Rendell, Peg Rawes, and Barbara Penner.

As exciting as the papers from architectural design are, the history and theory papers in this collection further demonstrate the innovative research presented at this conference. These papers represent original contributions to knowledge on various levels: Amy Thomas' sociology of financial transactions and the way it shapes the city (Thomas 2014); Anna Hoare's exploration of the paradoxes of gypsy legislation in the UK (Hoare 2014); and Kalliopi Amygdalou's breaking of East and West dichotomies in her investigation the involvement of two Beaux arts architects in the design of Izmir and Thessaloniki (Amygdalou 2014).

It is fair to say that each contribution from the history and theory of architecture has taken some of the threads set out by previous Bartlett generations further. Thomas is 
probably the best example of this. As a former disciple of Adrian Forty, she embodies his spirit on different levels. The first is that she stresses and includes first hand observation into her research, concluding that her research on the financial markets in the city really started by questioning the presence of the network of alleys and pedways in the city. And second, linking the social with the spatial, and, as such, telling a story about the building and transformation of the street in the financial capital of London from a place of financial transaction to one of leisure. Through this narrative, we witness a clear process that draws our attention to the role and significance of the streets and offices to economic, social, and political activities in the city. The obsession with experiencing the wall or other elements that make a space a home or an office can also be found in Hoare's work. Her anthropological work in the field enabled her to draw out the contradictions and anomalies in the current gypsy legislation. It is possible also to reflect on Amygdalou's research as an indirect extension of the work done on the process of architecture by, for example, Murray Fraser, who has done excellent work on mapping the dialogues, interrelations, and influences between American and British Architecture on the transatlantic space. Amygdalou pushes these boundaries further by undertaking an archeological investigation into the whereabouts of two architects/ planners of Izmir and Thessaloniki to conclude that ideas of the West and the Orient are meshed with one another. Dividing the world up into 'the West' and 'the Orient' is indeed a simplification, a point emphasized by Amygdalou.

Without simplifying matters too much or sounding too pragmatic, the continual dialogue between history and theory, architectural designers, and all others dealing with space can and will improve our understanding of the complex processes that consciously and unconsciously govern our daily lives. By listing the relation between theory and practice, I want to postulate that we have to stop talking about two separate programs. Architectural Design programs should not be, and cannot be, seen as something distinct from the History and Theory program. It is our hope that by pointing out some of the possible relations and mutual interests this distinction can be corrected over time.

We would like to thank all contributors and other members of the Bartlett faculty for all their assistance in putting this publication together, as well as the Bartlett Architecture Research Fund for financing the print version.

\section{References}

Amygdalou, K 2014 Building the Nation at the Crossroads of 'East' and 'West': Ernest Hébrard and Henri Prost in the near East. Opticon1826 (16):15, DOI: http://dx.doi. org/10.5334/opt.bv

Buck, D N 2014 Drawing Sound as Landscape. Opticon1826 (16):16, DOI: http:// dx.doi.org/10.5334/opt.cb

Gould, P 2014 Antarctica Through The Archive: A Script. Opticon1826 (16):19, DOI: http://dx.doi.org/10.5334/opt.ca

Hoare, A E 2014 The View from the Traveller Site: Post-nomadic Subjects and the Material Relations of Permanent Temporary Dwelling. Opticon1826 (16):18, DOI: http://dx.doi.org/10.5334/opt.bz

Masing, E 2014 Mapping or Choreographing?: Redefining Musical Notation. Opticon1826 (16):21, DOI: http://dx.doi. org/10.5334/opt.by

Palmer, 02014 Ant Ballet: Phase I. Opticon1826 (16):14, DOI: http://dx.doi. org/10.5334/opt.ce

Roberts, D 2014 Telling Stories / Empty Words Build Empty Homes. Opticon 1826 (16):17, DOI: http://dx.doi.org/10.5334/ opt.bq

Roberts, D and Thomas, A 2013 Introduction: Harmony and Discord. In: $P h D$ 
Research Projects 2013. The Bartlett Thomas, A 2014 Money Walks | The EcoSchool of Architecture: 6-7.

nomic Role of the Street in the City

Sotomayor, C 2014 Department of Decay. of London 1947-1993. Opticon1826 Opticon1826 (16):22, DOI: http://dx.doi. org/10.5334/opt.bx (16):20, DOI: http://dx.doi.org/10.5334/ opt.bl

How to cite this article: Aelbrecht, W 2014 Introduction: Some Thoughts on Research Programs in Architecture. Opticon1826, (16): 23, pp.1-5, DOl: http://dx.doi.org/10.5334/opt.cf

Published: 16 October 2014

Copyright: (c) 2014 The Author(s). This is an open-access article distributed under the terms of the Creative Commons Attribution 3.0 Unported License (CC-BY 3.0), which permits unrestricted use, distribution, and reproduction in any medium, provided the original author and source are credited. See http://creativecommons.org/licenses/by/3.0/. ] $\mathbf{u}\left[\begin{array}{l}\text { Opticon1826 is a peer-reviewed open access journal published by } \\ \text { Ubiquity Press }\end{array}\right.$ 